example of the use of measurements in serum or urine of tumour-produced substances in the diagnosis of certain tumours.

1 Cunliffe, W. J., et al., Lancet, 1968, 2, 63.

Williams, E. D., fournal of Clinical Pathology, 1967, 20, 395.

Williams, E. D., Karim, S. M. M., and Sandler, M., Lancet, 1968, 1, 22. Baylin, S. B., Beaven, M. A., Engelman, K., Sjoerdsma, A., New England Fournal of Medicine, 1970, 283, 1239

Baylin, S. B., Beaven, M. A., Keiser, H. R., Tashjian, A. H., and Melvin, K. E. W., Lancet, 1972, 1, 455

- Baylin, S. B., Beaven, M. A., Buja, L. M., and Keiser, H. R., American fournal of Medicine, 1972, 53, 723.

${ }^{7}$ Melvin, K. E. W., Miller, H. J., and Tashjian, A. H., New England fournal of Medicine, 1971, 285, 1115 .

\section{Vitreous Surgery}

New surgical techniques, instruments, and vitreous substitutes have opened an exciting era in the field of surgery of the vitreous of the eye. Cases of retinal detachment, which have hitherto been thought inoperable by conventional means, are being treated successfully with increasing frequency. Because of the failure of chemical and drug therapy in the treatment of vitreous haemorrhage, ophthalmic surgeons are turning to mechanical means of removing opaque vitreous from the eye.

Miniature scissors have recently been devised which enable vitreous bands and membranes to be cut in order to release vitreous traction on the retina. The blades are $5 \mathrm{~mm}$ in length and the part that enters the eye has a diameter of $1.6 \mathrm{~mm} .^{1}$ An instrument with an inflatable balloon at its tip has been used in positioning detached retina and in breaking adhesions between the detached retinal flap of a giant tear and the underlying retina in order to make it mobile and more accessible to surgery. ${ }^{2}$

The most significant advance in vitreous surgery has been the introduction of the vitreous infusion suction cutter, which has made seemingly untreatable disease of the vitreous treatable. The instrument, which is the size of a fountain pen, consists of three parts: an electric micromoter that drives the cutting mechanism; a suction system; and an infusion system. It is introduced into the vitreous cavity and simultaneously diseased vitreous is mechanically destroyed, aspirated, and replaced by a balanced salt solution, and vitreous strands are also eliminated. The action of the instrument is observed through a fundus contact lens with the operating microscope. Long-standing vitreous haemorrhage, vitreous membranes, and retinitis proliferans in diabetic patients, and difficult cases of retinal detachment with vitreous traction and giant tears, have been successfully treated by this method. The technique is tedious and long, requiring excellent surgical skill and judgement. So far the best results have been achieved in cases of long-standing vitreous haemorrhage. ${ }^{3}$ These heroic procedures should be confined to desperate cases, as treatment in the early stage of their development is hazardous.

The injection of vitreous substitutes into the vitreous cavity has been a useful adjunct in certain types of operations for retinal detachment. The purpose of these injections is to replenish the volume of the vitreous cavity and to restore normal intraocular pressure in eyes which are hypotonic after the drainage of subretinal fluid. By eliminating undesired folds in the retina and pushing the retina and retinal tears towards their required contact with the in- flamed choroid they also act as retinal splints. In certain cases vitreous substitutes are used to break down vitreous bands and membranes which, by exerting excessive pull on the retina, have rendered conventional methods of retinal reapposition ineffective.

Several liquids and gases are being tried with varying degrees of success. They include saline, human donor vitreous hyaluronic acid, silicone oil, and air. Attempts at vitreous transplantation by means of eye-bank donor vitreous have not proved to be entirely satisfactory owing to its rapid depolymerization after removal from the donor eye, rendering it no more viscid than water. Hyaluronic acid has been recently used with a moderate degree of success. It is superior to saline because of its higher viscosity and is well tolerated by the eye. Liquid silicone is a non-absorbable vitreous substitute with a high viscosity. Its use is reserved for patients with only one potentially useful eye which has an otherwise hopeless prognosis and no chance of cure by conventional procedures for treating retinal detachment. The long-term visual results with silicone are disappointing owing to the many late complications encountered, which include damage to the retinal cells. It has been used only in 37 hopeless cases of retinal detachment in the last nine years at the Retinal Unit of the High Holborn Branch of Moorfield Eye Hospital. ${ }^{4}$

Air is a useful substitute for vitreous and is absorbed a few days after its injection into the eye. Because of its low specific gravity its location within the eye can be controlled by altering the position of the patient's head postoperatively. This is of particular value in the treatment of giant retinal tears. ${ }^{5}$ Its main disadvantage is that it makes postoperative fundoscopy difficult.

The perfect vitreous substitute should be a gel with the same physical and optical properties as vitreous. Unfortunately gels cannot be injected through needles without fracturing them, and much more research in this field is necessary.

1 Couvillion, G. C., Freeman, H. M., and Schepens, C. L., Archives of Ophthalmology, 1970, 83, 722 .

2 Freeman, H. M., Couvillion, G. C., and Schepens, C. L., Archives of Ophthalmology, 1970, 83, 715 .

3 Machemer, R., Buettner, H., Norton, E. W. D. and Parel, J. M., Transactions of the American Academy of Ophthalmology and Otolaryngology, 1971, 75, 813.

4 Kanski, J. J., and Daniel, R., British fournal of Ophthalmology (in press).

5 Norton, E. W. D., Aaberg, T., Fung, W., and Curtin, V. T., American fournal of Ophthalmology, 1969, 68, 1011.

\section{Pilot Error}

The development of aircraft has brought them to a point where they can be flown by more automatic control than many airports permit. A high proportion are capable of partial automatic landing down to a height of 30 metres and a visual range on the runway of $\mathbf{4 0 0}$ metres, yet few airports allow this degree of automation, though Heathrow does do so. That pilots are capable of error like the rest of us is unfortunately true, as shown by a number of recent inquiries. But aircraft accidents remain a relatively rare circumstance in mass transportation. Much the largest proportion occur in the immediate neighbourhood of airports and are related to take-off and landing. Consequently the task that pilots undertake and the strains imposed on them during this part of the aircraft's flight, while being of special con- 